\title{
Front Matter: Volume 7815
}

, "Front Matter: Volume 7815," Proc. SPIE 7815, Quantum Communications and Quantum Imaging VIII, 781501 (9 September 2010); doi:

$10.1117 / 12.876295$ SPIE. Event: SPIE Optical Engineering + Applications, 2010, San Diego, California, 


\section{PROCEEDINGS OF SPIE}

\section{Quantum Communications and Quantum Imaging VIII}

Ronald E. Meyers

Yanhua Shih

Keith S. Deacon

Editors

2, 4-5 August 2010

San Diego, California, United States

Sponsored and Published by

SPIE

Volume 7815 
The papers included in this volume were part of the technical conference cited on the cover and title page. Papers were selected and subject to review by the editors and conference program committee. Some conference presentations may not be available for publication. The papers published in these proceedings reflect the work and thoughts of the authors and are published herein as submitted. The publisher is not responsible for the validity of the information or for any outcomes resulting from reliance thereon.

Please use the following format to cite material from this book:

Author(s), "Title of Paper," in Quantum Communications and Quantum Imaging VIII, edited by Ronald E. Meyers, Yanhua Shih, Keith S. Deacon, Proceedings of SPIE Vol. 7815 (SPIE, Bellingham, WA, 2010) Article CID Number.

ISSN 0277-786X

ISBN 9780819483119

Published by

SPIE

P.O. Box 10, Bellingham, Washington 98227-0010 USA

Telephone +1 3606763290 (Pacific Time) · Fax +1 3606471445

SPIE.org

Copyright (C) 2010, Society of Photo-Optical Instrumentation Engineers

Copying of material in this book for internal or personal use, or for the internal or personal use of specific clients, beyond the fair use provisions granted by the U.S. Copyright Law is authorized by SPIE subject to payment of copying fees. The Transactional Reporting Service base fee for this volume is $\$ 18.00$ per article (or portion thereof), which should be paid directly to the Copyright Clearance Center (CCC), 222 Rosewood Drive, Danvers, MA 01923. Payment may also be made electronically through CCC Online at copyright.com. Other copying for republication, resale, advertising or promotion, or any form of systematic or multiple reproduction of any material in this book is prohibited except with permission in writing from the publisher. The CCC fee code is 0277-786X/10/\$18.00.

Printed in the United States of America.

Publication of record for individual papers is online in the SPIE Digital Library.

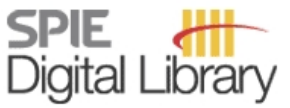

SPIEDigitalLibrary.org

Paper Numbering: Proceedings of SPIE follow an e-First publication model, with papers published first online and then in print and on CD-ROM. Papers are published as they are submitted and meet publication criteria. A unique, consistent, permanent citation identifier (CID) number is assigned to each article at the time of the first publication. Utilization of CIDs allows articles to be fully citable as soon they are published online, and connects the same identifier to all online, print, and electronic versions of the publication. SPIE uses a six-digit CID article numbering system in which:

- The first four digits correspond to the SPIE volume number.

- The last two digits indicate publication order within the volume using a Base 36 numbering system employing both numerals and letters. These two-number sets start with 00, 01, 02, 03, 04, $05,06,07,08,09,0 A, 0 B \ldots 0 Z$, followed by 10-1Z, 20-2Z, etc.

The CID number appears on each page of the manuscript. The complete citation is used on the first page, and an abbreviated version on subsequent pages. Numbers in the index correspond to the last two digits of the six-digit CID number. 


\section{Contents}

vii Conference Committee
ix Introduction

\section{QUANTUM IMAGING I}

781502 Soft-metric-based information reconciliation techniques for QKD (Invited Paper) [7815-01] M. Mondin, Politecnico di Torino (Italy); F. Daneshgaran, California State Univ. (United States); M. Delgado, F. Mesiti, Politecnico di Torino (Italy)

781503 Infrared two-color ghost imaging using entangled beams (Invited Paper) [7815-02]

C. C. Kim, G. Kanner, Northrop Grumman Electronic Systems (United States)

781506 Quantum ghost imaging (Invited Paper) [7815-05]

R. E. Meyers, K. S. Deacon, U.S. Army Research Lab. (United States); Y. Shih, Univ. of Maryland, Baltimore County (United States)

\section{QUANTUM TECHNOLOGY I}

781508 Study on noise reduction in up-conversion single photon detectors (Invited Paper) [7815-07] L. Ma, O. Slattery, X. Tang, National Institute of Standards and Technology (United States)

781509 Controlled placement of single photon sources for quantum integration (Invited Paper) [7815-08]

E. Waks, C. Ropp, R. Probst, Z. Cummins, R. Kumar, Univ. of Maryland, College Park (United States); A. Berglund, National Institute of Standards and Technology (United States); S. Raghavan, J. Fourkas, B. Shapiro, Univ. of Maryland, College Park (United States)

\section{QUANTUM TECHNOLOGY II}

$78150 \mathrm{~A}$ Upconversion as a tool for characterization and preparation of photonic quantum states (Invited Paper) [7815-09]

K. A. O'Donnell, Ctr. de Investigación Científica y de Educación Superior de Ensenada (Mexico); A. B. U'Ren, Univ. Nacional Autónoma de México (Mexico)

7815 OC Impurities in diamond: a new revival for quantum optics (Invited Paper) [7815-34]

S. Castelletto, I. Aharonovich, C. H. Su, S. Prawer, The Univ. of Melbourne (Australia)

\section{ENTANGLEMENT}

7815 OD Quantum random number generator using photon-number path entanglement (Invited Paper) [7815-11]

O. Kwon, Y.-W. Cho, Y.-H. Kim, Pohang Univ. of Science and Technology (Korea, Republic of) 
$7815 \mathrm{OE} \quad$ How can we minimize errors in a linear-optics quantum gate? [7815-37]

T. Nagata, R. Okamoto, M. Tanida, Hokkaido Univ. (Japan) and Osaka Univ. (Japan);

H. F. Hofmann, Hiroshima Univ. (Japan); S. Takeuchi, Hokkaido Univ. (Japan) and Osaka Univ. (Japan)

$7815 \mathrm{OH}$ Efficient photon pair sources based on silicon-on-insulator microresonators (Invited Paper) [7815-15]

J. Chen, National Institute of Standards and Technology (United States) and Univ. of Maryland, College Park (United States); Z. H. Levine, National Institute of Standards and Technology (United States); J. Fan, A. Migdall, National Institute of Standards and Technology (United States) and Univ. of Maryland, College Park (United States)

\section{QUANTUM IMAGING II}

7815 Ol Quantum ghost imaging experiments at ARL (Invited Paper) [7815-17]

R. E. Meyers, K. S. Deacon, U.S. Army Research Lab. (United States)

$78150 \mathrm{~J}$ Towards improved end-to-end system efficiency of photon pair systems (Invited Paper) [7815-18]

A. Ling, J. Fan, A. Migdall, National Institute of Standards and Technology (United States) and Univ. of Maryland, College Park (United States)

$7815 \mathrm{OL}$ Ghost imaging in reflection: resolution, contrast, and signal-to-noise ratio (Invited Paper) [7815-20]

N. D. Hardy, J. H. Shapiro, Massachusetts Institute of Technology (United States)

\section{QUANTUM COMMUNICATIONS}

781500 Towards high-rate quantum key distribution using quantum frames (Invited Paper) [7815-23] X. Mo, I. Lucio Martinez, P. Chan, Univ. of Calgary (Canada); S. Hosier, SAIT Polytechnic (Canada); W. Tittel, Univ. of Calgary (Canada)

7815 OP Quantum stream cipher beyond the Shannon limit of symmetric key cipher and the possibility of experimental demonstration (Invited Paper) [7815-24]

O. Hirota, T. Iwakoshi, M. Sohma, F. Futami, Tamagawa Univ. (Japan)

\section{QUANTUM INFORMATION SCIENCE}

7815 OR Analogue factoring algorithm based on polychromatic interference [7815-40] V. Tamma, Univ. of Maryland, Baltimore County (United States); A. Garuccio, Univ. degli Studi di Bari (Italy); Y. Shih, Univ. of Maryland, Baltimore County (United States)

7815 OT Graph state secret sharing in higher-dimensional systems (Invited Paper) [7815-26] B. Fortescue, A. Keet, Univ. of Calgary (Canada); D. Markham, LTCI-CNRS, Telecom ParisTech (France); B. C. Sanders, Univ. of Calgary (Canada)

7815 OU Hybrid information processing (Invited Paper) [7815-27]

B. C. Jacobs, The Johns Hopkins Univ. (United States) 
$78150 \mathrm{~V}$ Phase transitions in systems of interacting photons: quantum optics, quantum information, condensed matter and the Jaynes-Cummings-Hubbard model (Invited Paper) [7815-28]

A. D. Greentree, The Univ. of Melbourne (Australia)

\section{POSTER SESSION}

$781511 \quad$ Narrow-band photon pairs generated from spontaneous parametric down conversion in a Bragg-grating enhanced waveguide (Invited Paper) [7815-12]

L. Yan, Univ. of Maryland, Baltimore County (United States); L. Ma, X. Tang, National Institute of Standards and Technology (United States)

781512 Review of representative free-space quantum communications experiments (Invited Paper) [7815-22]

A. Tunick, T. Moore, K. Deacon, R. Meyers, U.S. Army Research Lab. (United States)

781513 Storage and retrieval of thermal light in warm atomic vapor [7815-38]

Y.-W. Cho, Y.-H. Kim, Pohang Univ. of Science and Technology (Korea, Republic of)

781514 Effects depolarizing quantum channels on BB84 and SARG04 quantum cryptography [7815-39]

Y.-C. Jeong, Y.-S. Kim, Y.-H. Kim, Pohang Univ. of Science and Technology (Korea, Republic of)

Author Index 
Downloaded From: https://www.spiedigitallibrary.org/conference-proceedings-of-spie on 26 Apr 2023

Terms of Use: https://www.spiedigitallibrary.org/terms-of-use 


\title{
Conference Committee
}

\author{
Program Track Chairs
}

Stephen M. Hammel, Space and Naval Warfare Systems Center, San Diego (United States)

Alexander M. J. van Eijk, TNO Defense, Security and Safety

(Netherlands)

Conference Chairs

Ronald E. Meyers, Army Research Laboratory (United States)

Yanhua Shih, University of Maryland, Baltimore County (United States)

Keith S. Deacon, Army Research Laboratory (United States)

Program Committee

Stefania A. Castelletto, The University of Melbourne (Australia)

Milena D'Angelo, Università degli Studi di Bari (Italy)

Richard J. Hughes, Los Alamos National Laboratory (United States)

Yoon-Ho Kim, Pohang University of Science and Technology (Korea, Republic of)

Todd B. Pittman, University of Maryland, Baltimore County (United States)

Barry C. Sanders, University of Calgary (Canada)

Alexander V. Sergienko, Boston University (United States)

Dmitry V. Strekalov, Jet Propulsion Laboratory (United States)

Shigeki Takeuchi, Hokkaido University (Japan)

Arnold Tunick, U.S. Army Research Laboratory (United States)

Xiao Tang, National Institute of Standards and Technology (United States)

Zhi Zhao, Oak Ridge National Laboratory (United States)

\section{Session Chairs}

1 Quantum Imaging I

Ronald E. Meyers, U.S. Army Research Laboratory (United States)

Keith S. Deacon, U.S. Army Research Laboratory (United States)

2 Quantum Technology I

Ronald E. Meyers, U.S. Army Research Laboratory (United States)

Keith S. Deacon, U.S. Army Research Laboratory (United States) 
Ronald E. Meyers, U.S. Army Research Laboratory (United States) Keith S. Deacon, U.S. Army Research Laboratory (United States)

Ronald E. Meyers, U.S. Army Research Laboratory (United States)

Keith S. Deacon, U.S. Army Research Laboratory (United States)

5 Quantum Imaging II

Ronald E. Meyers, U.S. Army Research Laboratory (United States)

Keith S. Deacon, U.S. Army Research Laboratory (United States)

6 Quantum Communications

Ronald E. Meyers, U.S. Army Research Laboratory (United States)

Keith S. Deacon, U.S. Army Research Laboratory (United States)

7 Quantum Information Science

Ronald E. Meyers, U.S. Army Research Laboratory (United States)

Keith S. Deacon, U.S. Army Research Laboratory (United States)

8 Quantum Information, Imaging, and Technology

Ronald E. Meyers, U.S. Army Research Laboratory (United States)

Keith S. Deacon, U.S. Army Research Laboratory (United States) 


\section{Introduction}

It is my pleasure to write the foreword to the proceedings of the very successful and very exciting SPIE Quantum Communications and Quantum Imaging VIII conference, which was held in San Diego, California, 2, 4-5 August 2010. This is actually the ninth of our ongoing series of international conferences at the SPIE annual Optics + Photonics meeting providing new theoretical and experimental results and insights into the fundamentals of quantum communications and imaging science and technology. The purpose of this conference is to bring together scientists performing fundamental research in quantum communications and quantum imaging for the benefit of both. Distinguished scientists from many countries presented state-of-the-art scientific papers on quantum communications and quantum imaging and stimulated lively discussions with audience participants. This conference is known for the spirited insightful discussions, which continue after the presentations and after the sessions.

Scientific highlights included research on the role of the quantum properties in quantum imaging as well as experimental methods for quantum imaging with entanglement and incoherent thermal sources; In particular, the concept natural nonfactorizeability of the ghost imaging two-photon amplitude correlations was explored. It leads to experiments in compressive turbulence-free ghost imaging. Other research demonstrated quantum imaging methods to overcome imaging aberrations. In addition, man-made compressive quantum inspired ghost imaging was explored with pseudo random micro-pixel illumination and pseudo-randomly displace Bessel beam illumination and using compressive sensing. Analysis was presented that indicates various types of ghost imaging exhibit higher signal to noise ratios than conventional laser radars. Quantum communications was reviewed in the conference and new fiber and free-space technologies were presented for achieving high speed quantum communications. Research was presented on high speed and high security quantum encryption and quantum key distribution methodologies and their expanding role with national programs in bringing increased communications security and bandwidth. For the first time it was shown that light can factor numbers having values over one-million and determine primes. New fundamental relations in quantum properties of thermal light were presented and experimentally verified with determination of Bell states of thermal light. With regards to new sources of radiation we found that diamonds are achieving a greatly increased capability as single photon sources. It was also demonstrated how slow light can be used to achieve memory of thermal light photon statistics. Research in superresolution is achieving unprecedented subwavelength resolution. The close relation between quantum communications

and quantum imaging continues to be demonstrated by important scientific and technological achievements. 
I would like to thank Professor Yanhua Shih of the University of Maryland, Baltimore County and Keith Deacon of the Army Research Laboratory for helping to organize the conference and for providing high standards and achievement in quantum imaging and quantum science. In particular, I would like to thank Keith Deacon for helping chair the sessions. A debt is due to each on the program committee for providing recommendations and contacts of those who attended.

I look forward to meeting all of our participants at our next SPIE Quantum Communications and Quantum Imaging conference, 21-25 August 2011 in San Diego, California.

\section{Ronald E. Meyers Yanhua Shih Keith S. Deacon}

